\title{
ABNORMAL SIGNAL AVERAGED ECG AFTER SURGICAL REPAIR OF TETRALOGY OF FALLOT — A Combined Analysis in the Time and Frequency Domain -
}

\author{
Suguru Matsuoka, M.D., Hiroshi Akita, M.D. \\ Yasunobu Hayabuchi, M.D., Yoshiyuki Taguchi, M.D. \\ Masahiro Kubo, M.D., Tetsuya Kitagawa, M.D* \\ ItSUo Katoh, M.D** and Kunio II, M.D.**
}

\begin{abstract}
Purpose: The clinical significance of abnormal signal averaged ECG (SA-ECG) determined by time and frequency domain analyses was assessed in tetralogy of Fallot patients after surgical repair, and the methods of analysis were compared. Materials and methods: SA-ECG was performed in 42 patients (mean age, 9.4 years) after radical surgical repair of tetralogy of Fallot, and in 11 preoperative patients (mean age, 2.6 years). Abnormal SA-ECGs were defined by time domain analysis (vector magnitude method) and frequency domain analysis (fast Fourier transformation).

Results: Abnormal SA-ECGs were recognized in 10 postoperative, patients ( 3 by time domain and 9 by frequency domain, analysis), but in none of the preoperative patients. Three patients with abnormal SA-ECGs had nonsustained ventricular tachycardia, 5 others had premature ventricular contractions, and the remaining 2 had no ventricular tachyarrhythmias documented by $24 \mathrm{~h}$ Holter monitoring. Patients with abnormal SA-ECGs more commonly had ST-T segment depression on standard ECG during exercise (8/10 versus 8/32, $\mathrm{p}<0.001$ ), a history of resection of a hypertrophic septoparietal muscle band $(8 / 10$ versus $2 / 32, p<0.001)$ and histologically documented myocardial fibrosis at radical surgical repair $(9 / 10$ versus $5 / 19, \mathrm{p}<0.002)$.

Conclusion: A Combination of time and frequency domain analyses was necessary to detect abnormal SA-ECGs in postoperative patients because of ventricular conduction disturbance. This technique might increase our ability to identify patients at risk of ventricular tachyarrhythmia, or those with underlying myocardial abnormalities.

(Jpn Circ J 1993; 57: 841-850)
\end{abstract}

$\mathbf{T}^{\mathrm{u}}$

exposure of hypertrophic cardiac muscle to chronic hypoxia and further surgical interventions, such as ventriculo-

Key words:

Signal-averaged ECG

Late potentials

Tetralogy of Fallot

Ventricular arrhythmia tomy, ventricular septal defect closure, and infundibular resection, can result in cardiac injury in tetralogy of Fallot. Such myocardial damage can produce local fibrosis and ventricular conduction disturbances, which may then contribute to ventricular arrhythmias after surgical repair ${ }^{-5}$ Histological

(Received April 25, 1992; accepted January 22, 1993)

Department of Pediatrics, *Department of Cardiovascular Surgery, and **First Department of Pathology Tokushima University Hospital, Kuramoto-cho, Tokushima-shi, Tokushima, Japan 770

Mailing address: Suguru Matsuoka, M.D., Department of Pediatrics, Tokushima University Hospital, Kuramotocho, Tokushima-shi, Tokushima 770, Japan 


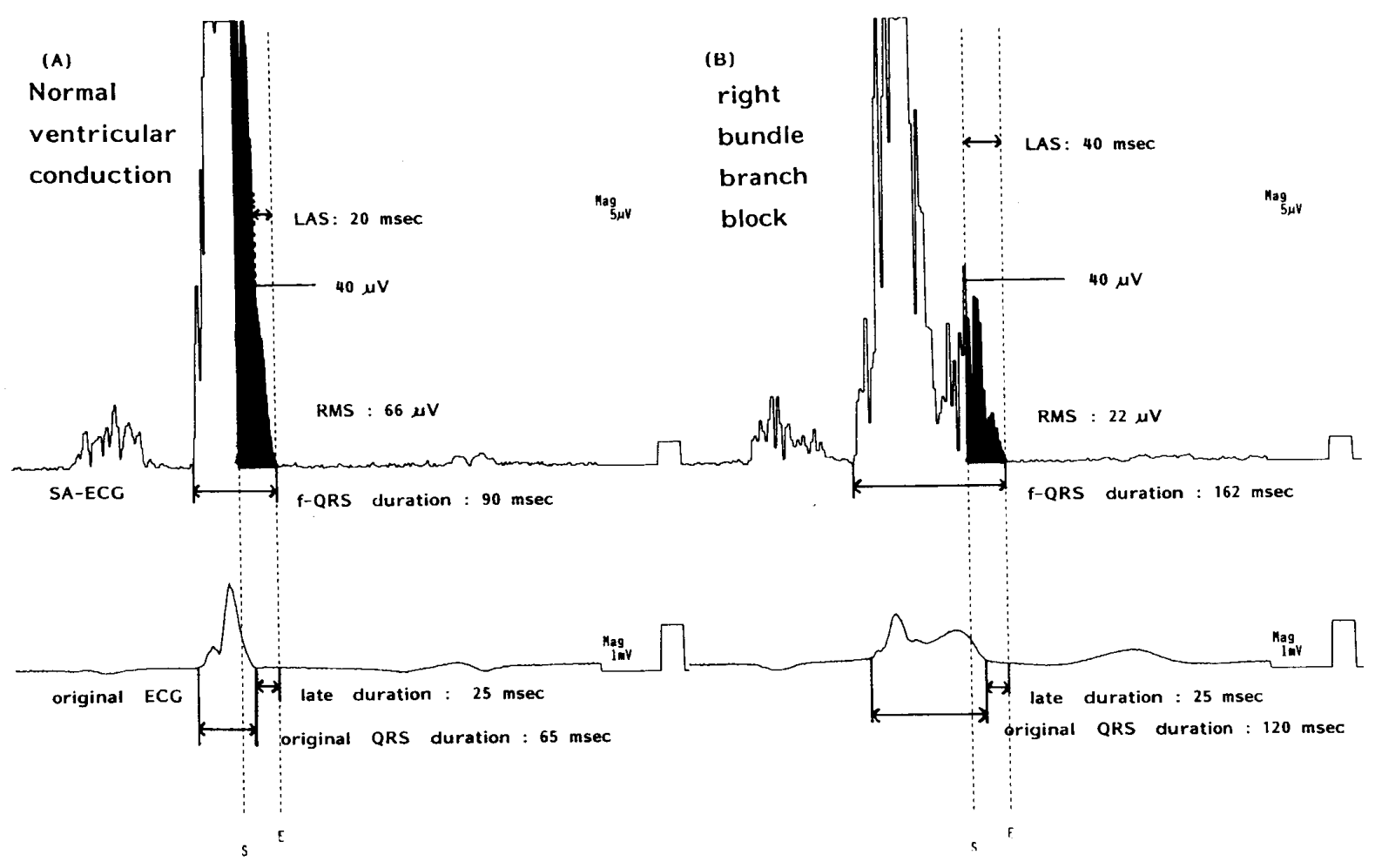

Fig.1. Quantitative time domain analysis of the wave form of a signal-averaged electrocardiogram (SA-ECG) and a nonfiltered original electrocardiogram.

(A) Recording from a healthy volunteer. Note the abrupt decay in voltage at the end of the QRS complex. The root-mean-square voltage of the QRS complex in the last $40 \mathrm{msec}$ (RMS) is shaded in black and is $66 \mu \mathrm{V}$. The filtered-QRS (fQRS) duration is $90 \mathrm{msec}$, and the late duration is $25 \mathrm{msec}$.

(B) Recording from a patient with right bundle branch block who had undergone intracardiac repair for tetralogy of Fallot. Note the lower root-mean-square voltage (RMS) $(22 \mu \mathrm{V})$ and longer filtered-QRS duration $(162 \mathrm{msec})$. The fragmented signal at $40 \mu \mathrm{V}$ (arrow) affects the duration of low amplitude signal of the filtered-QRS $<40 \mu \mathrm{V}$ (LAS), but the late duration was not affected (25 $\mathrm{msec})$.

abnormalities may cause localized slow conduction and lead to reentrant ventricular arrhythmias or increased ventricular automaticity ${ }^{6-9}$ Delayed and fragmented low action potentials have been detected at multiple sites within the right ventricle in postoperative tetralogy of Fallot patients by endocardial and epicardial mapping1,10,11

SA-ECG was developed to detect late potentials, and has recently been applied to postoperative patients using Simson's method to identify individuals at high risk of ventricular tachycardia! ${ }^{12-14}$

The present study investigated abnormal SA-ECGs in tetralogy of Fallot patients by using SA-ECG combined with time and frequency domain analysis in relation to spontaneous ventricular arrhythmias and the effects of surgical intervention.

\section{METHODS}

\section{Patients}

Forty-two tetralogy of Fallot patients aged 5 to 23 years (mean age: 9.6 years) were studied. The time interval from intracardiac repair to this study ranged from 3 to 11 years (mean interval: 5.7 years). Thirty-six of these 42 postoperative patients had right bundle branch block. None of the patients showed atrioventricular block on a standard 12-lead electrocardiogram. Fourteen patients had a normal QRS axis postoperatively, and the other 28 remained in right axis deviation, which was recognized in all patients before intracardiac repair.

Malignant ventricular arrythmias were noted in 10 patients postoperatively by $24 \mathrm{~h}$ Holter monitoring. A malignant arrhythmia 

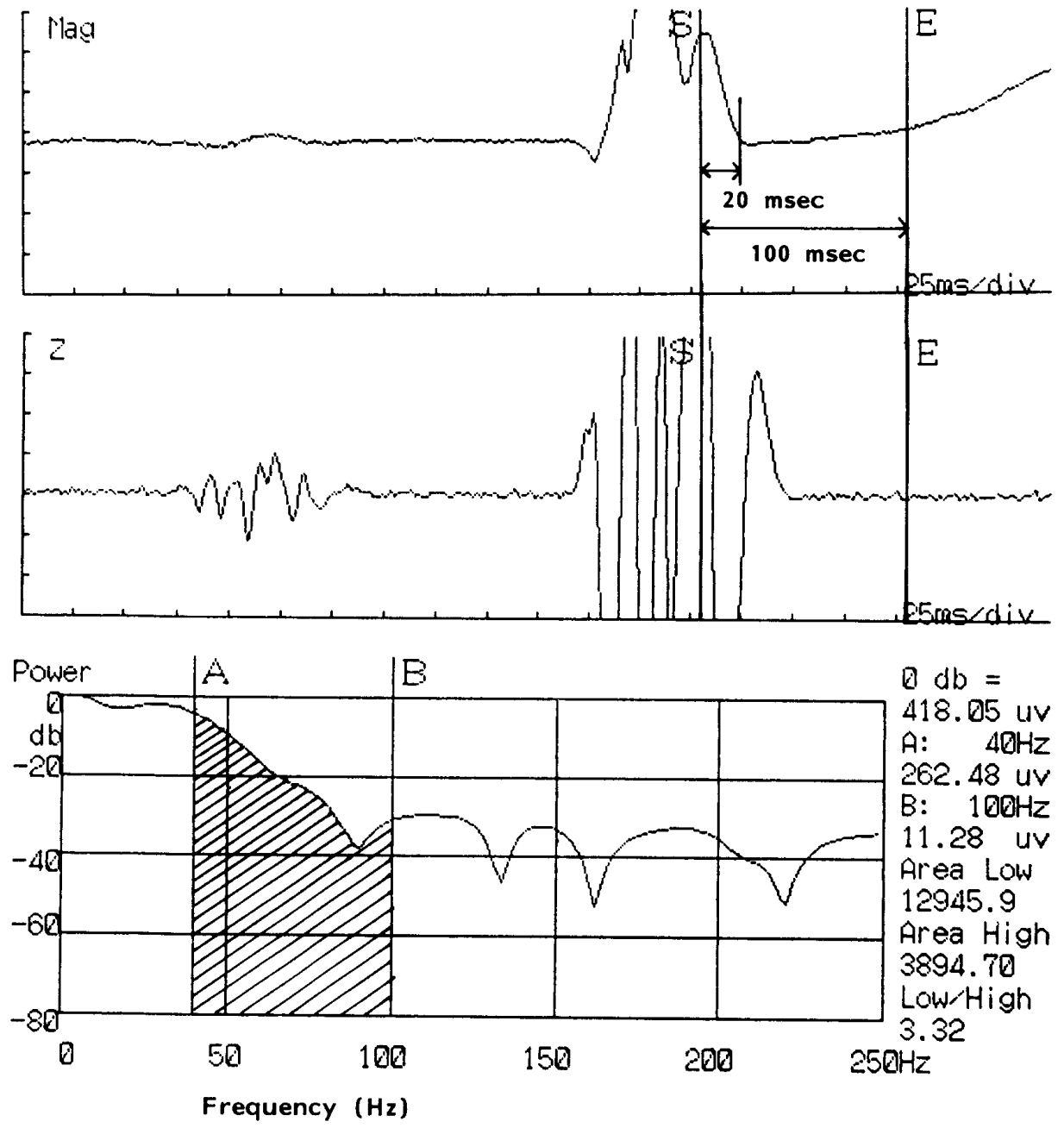

Fig.2. Frequency domain analysis of the terminal QRS and ST-segment. The segment was defined from $20 \mathrm{msec}$ before the end of the nonfiltered QRS complex (vectorsummed magnitude) to $80 \mathrm{msec}$ after its completion. The power spectrum in the high frequency component was evaluated as the low/high area ratio.

was defined as a documented episode of ventricular arrhythmias (Lown's grade III or higher) consisting of multiform premature ventricular contractions, couplets, or ventricular tachycardia. Six patients had couplet premature ventricular contractions, which were defined as uniform broad QRS complexes lasting for 2 beats. One patient had multiphasic premature ventricular contractions. Three patients had nonsustained ventricular tachycardia, which was defined as uniform broad QRS complexes lasting for more than 3 beats, persisting for up to $30 \mathrm{~s}$, and terminating spontaneously without any symptoms. In 1 patient with ventricular tachycardia, an electrophysiological study was performed and ventricular tachycardia was induced by a single extrastimulus to the right ventricular wall. All of the patients with ventricular arrhythmias were asymptomatic and were not receiving antiarrhythmic drugs. All of the patients underwent a double master 2-step test or Ergometer exercise test (generally those over 7 years of age) to detect ST-T depression (flat decline type and more than $0.1 \mathrm{mv}$ ) and ventricular arrhythmias occurring during exercise.

Intracardiac surgical repair for tetralogy of Fallot consisted of patch closure of the ventricular septal defect and repair of the right ventricular outflow tract. All of the patients underwent ventriculotomy in the right ventricular outflow tract, and incision or excision of the hypertrophic outlet septum. Ten patients also underwent resection of a hypertrophic septoparietal muscle band which was contributing to infundibular stenosis. In these cases, septoparietal muscle band was 


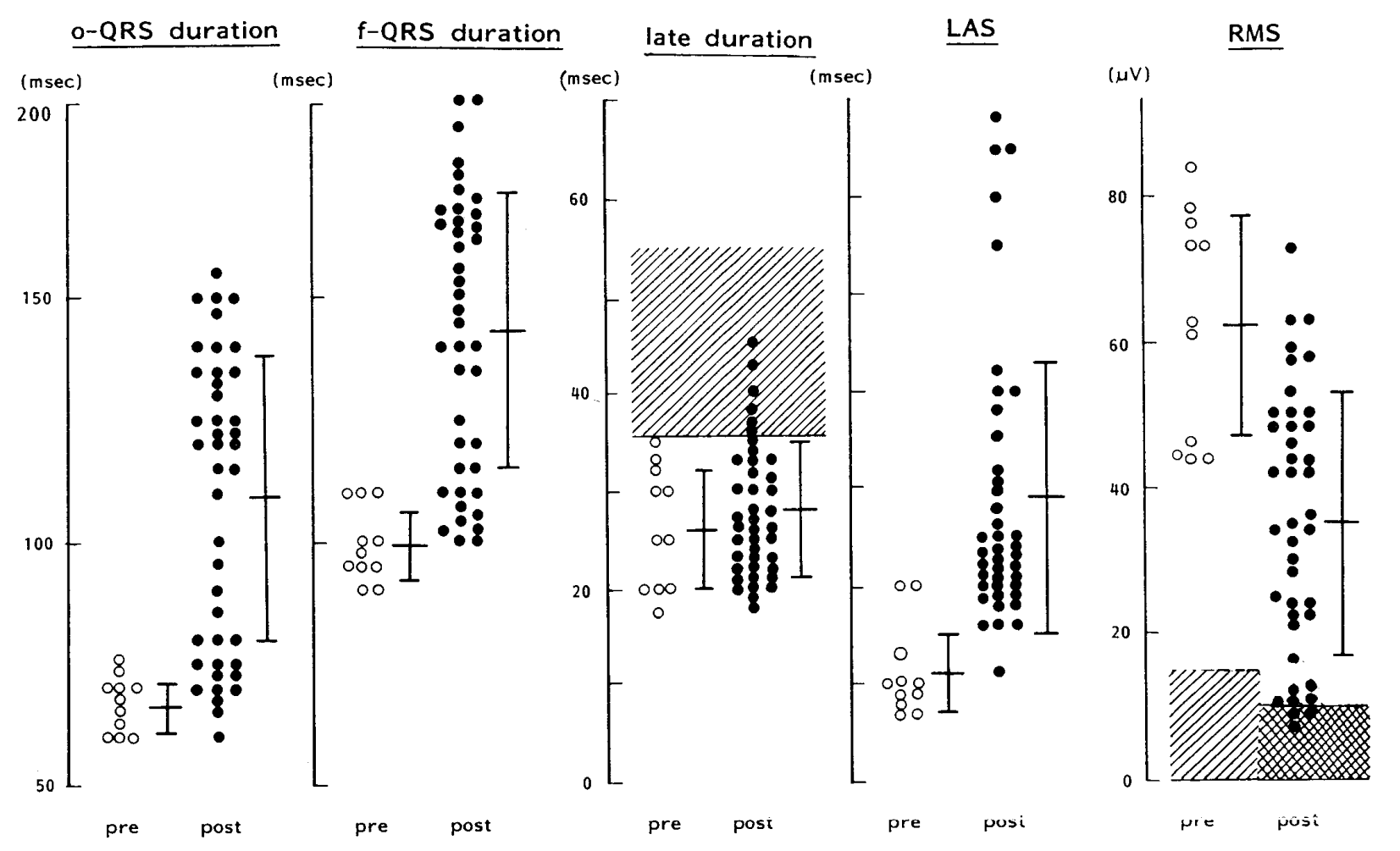

Fig.3. Time domain variables in preoperative and postoperative patients. The hatched area is abnormal based on the data obtained from healthy volunteers. Depending on the presence or absence of right bundle branch block, the abnormal area of root-mean-square voltage (RMS) was altered, and the cross-hatched area is abnormal in the presence of right bundle branch block. Note the prolongation of the nonfiltered-QRS (o-QRS) duration, filtered QRS (f-QRS) duration, and the duration of low amplitude signal (LAS), as well as the decrease of root-meansquare voltage in postoperative patients as a result of right bundle branch block. Open and closed circles represent data in preoperative and postoperative patients, respectively.

the septal limb of the crista supraventricularis that inserted into the anterior right ventricular wall.

Eleven other tetralogy of Fallot patients were also studied before intracardiac repair (age range: 1.0 to 4.5 years; mean age: 2.6 years). They all had normal ventricular conduction and right axis deviation on a standard ECG, and underwent a Blalock-Taussig shunt operation.

\section{Signal-Averaged Electrocardiography ECG)}

$(S A-$

SA-ECGs were recorded using a multipurpose electrocardiograph (Fukuda Denshi, VCM-3000). In each patient, 256 cycles were averaged during sinus rhythm and the noise level was maintained below $1 \mu \mathrm{V}$. The electrical signals were amplified and filtered at a frequency between 40 and $300 \mathrm{~Hz}$. The time domain was analyzed by the vector magnitude method, and was calculated as $\mathrm{V}=\sqrt{\mathrm{X}^{2}+\mathrm{Y}^{2}+\mathrm{Z}^{2}} \mathrm{X}, \mathrm{Y}$, and $\mathrm{Z}$ were modified bipolar leads, and the following signals were measured to estimate abnormal SAECGs in the time domain: nonfiltered QRS duration, filtered QRS duration, the duration of low amplitude signal of the filtered$\mathrm{QRS}<40 \mu \mathrm{V}$ (LAS), the late duration (from the end of the nonfiltered-QRS complex to the end of the filtered-QRS complex), and the root-mean-square voltage of the filteredQRS complex during its last $40 \mathrm{msec}$ (RMS) (Fig. 1).

Based on the data obtained in our hospital from 87 healthy volunteers aged $1-20$ years with and without right bundle branch block, abnormal SA-ECGs in the time domain were defined by 2 criteria, depending on whether the patient had ventricular conduction disturbance on the 12-lead ECG. In 68 healthy controls with normal ventricular conduction, 
low/high area ratio

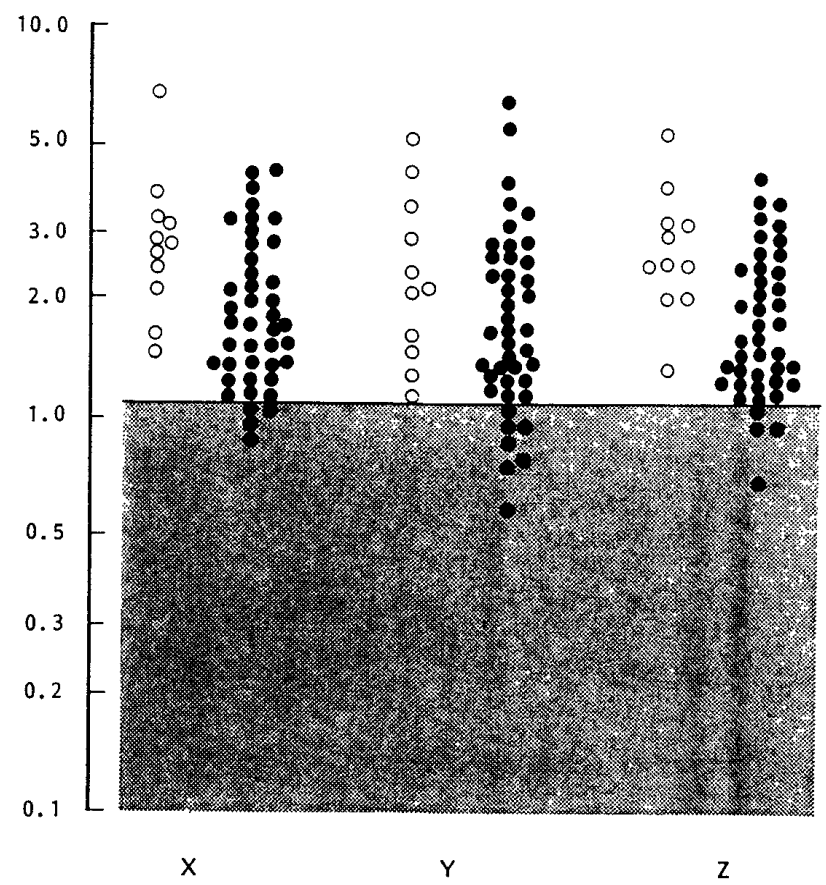

Fig.4. The low/high area ratio determined by frequency domain analysis in preoperative and postoperative patients. The hatched area is abnormal based on the data obtained in healthy volunteers. Note that all of the preoperative patients are in the normal area, but some of the postoperative patients are in the abnormal region. Open and closed circles represent data in preoperative and postoperative patients, respectively.

a late duration was less than $35 \mathrm{msec}$ and RMS was more than $15 \mu \mathrm{V}$. In 19 right bundle branch block patients with no apparent cardiac diseases, a late duration was less than $35 \mathrm{msec}$ and RMS was more than $10 \mu \mathrm{V}$.

For tetralogy of Fallot patients with normal ventricular conduction, a late duration $>35 \mathrm{msec}$ and $\mathrm{RMS}<15 \mu \mathrm{V}$ were used to define the presence of abnormal SAECGs. For patients with ventricular conduction disturbance, the 2 criteria were $35 \mathrm{msec}$ and $10 \mu \mathrm{V}$. The 2 studied groups, pre- and post-radical operation, were not age-matched. However, a root-mean-square voltage (RMS) and late duration in SA-ECG were constant among 68 healthy volunteers aged 1 to 20 years: RMS; $1-6 \mathrm{y}: 49 \pm 12 \mu \mathrm{V}, 6-12$ y: $49 \pm 12 \mu \mathrm{V}, 12-20$ y: $44 \pm 11 \mu \mathrm{V}$; late duration; $1-6$ y: $24 \pm 5 \mathrm{msec}, 6-12$ y: $20 \pm 5$ msec, $12-20$ y: $21 \pm 7 \mathrm{msec}$.

\section{Fast Fourier transformation method}

The segment of interest in SA-ECG was the terminal QRS and ST segment, which was defined as running from $20 \mathrm{msec}$ before the end of the nonfiltered-QRS complex to $80 \mathrm{msec}$ after its completion (Fig. 2). The nonfiltered QRS complex was defined on the basis of its vector-summed magnitude in the $\mathrm{X}, \mathrm{Y}$, and $\mathrm{Z}$ leads. This 100 -msec segment of filtered electrical signals in lead $X, Y$, and $\mathrm{Z}$ leads was multiplied point by point with a 4-term Blackman-Harris window to avoid edge discontinuities. The data points were set at the beginning of a 512-element array and the remaining points were set to zero. Fast Fourier transformation of the 512 points was then performed by a computer and the power spectrum was plotted on a logarithmic scale. The units of the ordinate were in decibels $(20 \mathrm{~dB}$ equaled an amplitude ratio of 10 , and $0 \mathrm{~dB}$ was defined by the peak amplitude).

An abnormal SA-ECG in the frequency domain was defined by the following criterion, that was again based on data obtained at our hospital from healthy volunteers. The criterion was a low/high spectral area ratio which was calculated as follows: the area of the power spectrum between 0 and $40 \mathrm{~Hz}$ was divided by the area of the power spectrum between 40 and $100 \mathrm{~Hz}$ (hatched area in Fig. 2). In 68 healthy controls with normal ventricular conduction, the area ratio was greater than 1.2. In 19 right bundle branch block patients with no apparent cardiac diseases, the area ratio was greater than 1.1. For tetralogy of Fallot patients, an area ratio $<1.1$ defined the presence of abnormal SA-ECGs, despite ventricular conduction disturbance.

\section{Histological study}

Twenty-nine specimens were obtained from the outlet septum and from the septoparietal muscle bands (10 specimens) at the time of surgery. The specimens were fixed in neutral formalin, embedded in paraffin, sectioned, and stained with hematoxylineosin and Mallory's azan stain.

\section{Statistical analysis}

Statistical differences were examined by Fisher's exact probability test and $p<0.05$ was considered significant. 
TABLE I CLINICAL CHARACTERISTICS OF THE POSTOPERATIVE PATIENTS WITH ABNORMAL SA-ECGs IN THE TIME AND/OR FREQUENCY DOMAIN ANALYSIS

\begin{tabular}{|c|c|c|c|c|c|c|c|}
\hline & \multirow{2}{*}{$\begin{array}{c}\text { Age } \\
(y r)\end{array}$} & \multirow{2}{*}{$\begin{array}{c}\text { Age at } \\
\text { surgery } \\
\quad(y r)\end{array}$} & \multirow{2}{*}{$\begin{array}{l}\text { resection of } \\
\text { septoparietal } \\
\text { band }\end{array}$} & \multicolumn{3}{|c|}{ 12-lead standard ECG } & \multirow{2}{*}{$\frac{24 h \text { monitoring }}{\text { ventricular arrhythmia }}$} \\
\hline & & & & QRS Axis & $B B B$ & $S T-T$ depression & \\
\hline $1 \diamond$ & 5 & 2 & yes & Normal & $R B B B$ & $I I, I I I, a V F$ & $P V C$ (couplet) \\
\hline $2 \diamond$ & 6 & 2 & yes & Normal & $R B B B$ & $V 1, V 2$ & PVC (multiphasic) \\
\hline $3 \diamond$ & 7 & 4 & no & Normal & $R B B B$ & - & PVC (couplet) \\
\hline $4 \diamond$ & 7 & 4 & no & Right & $R B B B$ & - & PVC (couplet) \\
\hline 50 & 8 & 5 & yes & Normal & $n . d$. & $I I, I I I, a V F$ & $V T$ (non-sustained) \\
\hline $6 \diamond$ & 8 & 6 & yes & Normal & $R B B B$ & $V 5, V 6$ & n.d. \\
\hline $7 \diamond$ & 12 & 3 & yes & Right & $R B B B$ & $V 1, V 2$ & $P V C$ (couplet) \\
\hline 80 & 14 & 4 & yes & Normal & $R B B B$ & $V 1, V 2$ & $V T$ (non-sustained) \\
\hline $9 \diamond$ & 15 & 10 & yes & Right & $R B B B$ & $V 1, V 2$ & $n . d$. \\
\hline 100 & 23 & 16 & yes & Normal & $R B B B$ & $V 5, V 6, I I, I I I, a V F$ & $V T$ (non-sustained) \\
\hline
\end{tabular}

$\bigcirc$; abnormal SA-ECGs shown by time domain analysis, $\diamond$; abnormal $S A-E C G$ shown by frequency domain analysis, (O); abnormal SA-ECG shown by both methods of analysis. n.d.; not detected, RBBB; right bundle branch block, PVC; premature ventricular contractions, VT; ventricular tachycardia.

TABLE II SIGNAL-AVERAGED ELECTROCARDIOGRAPHIC DATA OF PATIENTS WITH ABNORMAL SA-ECGs IN THE TIME AND/OR FREQUENCY DOMAIN ANALYSIS

\begin{tabular}{|c|c|c|c|c|c|c|c|}
\hline & \multicolumn{4}{|c|}{ Time Domain } & \multirow{2}{*}{\multicolumn{3}{|c|}{$\begin{array}{l}\text { Frequency Domain } \\
\text { low/high area ratio }\end{array}$}} \\
\hline & \multirow{2}{*}{$\begin{array}{c}f-Q R S \\
\text { duration } \\
\text { (msec) }\end{array}$} & \multirow{2}{*}{$\begin{array}{c}L A S \\
(m s e c)\end{array}$} & \multirow{2}{*}{$\begin{array}{c}\text { late } \\
\text { duration } \\
\text { (msec) }\end{array}$} & \multirow{2}{*}{$\begin{array}{l}R M S \\
(\mu V)\end{array}$} & & & \\
\hline & & & & & $X$ & $Y$ & $Z$ \\
\hline $1 \diamond$ & 104 & 23 & 26 & 58 & 3.2 & 4.0 & 0.7 \\
\hline $2 \diamond$ & 165 & 68 & 37 & 11 & 1.0 & 0.9 & 1.2 \\
\hline $3 \diamond$ & 165 & 22 & 33 & 25 & 1.2 & 1.0 & 1.2 \\
\hline $4 \diamond$ & 163 & 18 & 23 & 18 & 1.0 & 1.0 & 1.0 \\
\hline 50 & 140 & 60 & 45 & 9 & 1.5 & 2.7 & 2.6 \\
\hline $6 \diamond$ & 135 & 43 & 30 & 11 & 1.0 & 0.8 & 1.5 \\
\hline $7 \diamond$ & 150 & 24 & 22 & 23 & 1.2 & 0.8 & 1.3 \\
\hline $8 \bigcirc$ & 165 & 65 & 35 & 9 & 1.6 & 1.1 & 3.2 \\
\hline $9 \diamond$ & 172 & 20 & 19 & 45 & 0.9 & 0.6 & 1.0 \\
\hline 100 & 140 & 55 & 40 & 7 & 1.7 & 1.4 & 1.1 \\
\hline
\end{tabular}

$\bigcirc$; abnormality detected by time domain analysis, $\diamond ;$ abnormality detected by frequency domain analysis, (O); abnormality detected by both methods of analysis. $f$-QRS; filtered-QRS. LAS; duration of low amplitude signal of the filtered-QRS $<40 \mu \mathrm{V} . R M S$; root-mean-square voltage of the filtered-QRS complex during its last 40 msec.

\section{RESULTS}

The time domain data for preoperative and postoperative patients are presented in Fig. 3. The nonfiltered-QRS duration, the filtered-QRS duration and the duration of low amplitude signal (LAS) portion of the filtered QRS increased, and root-meansquare voltage (RMS) decreased significantly in postoperative patients because of right ventricular branch block. The late duration was not significantly affected despite the presence of right bundle branch block. While all of the preoperative patients had a late duration in the normal range, in some postoperative patients, late duration and the root-mean-square voltage (RMS) were abnormal compared with the data obtained in 


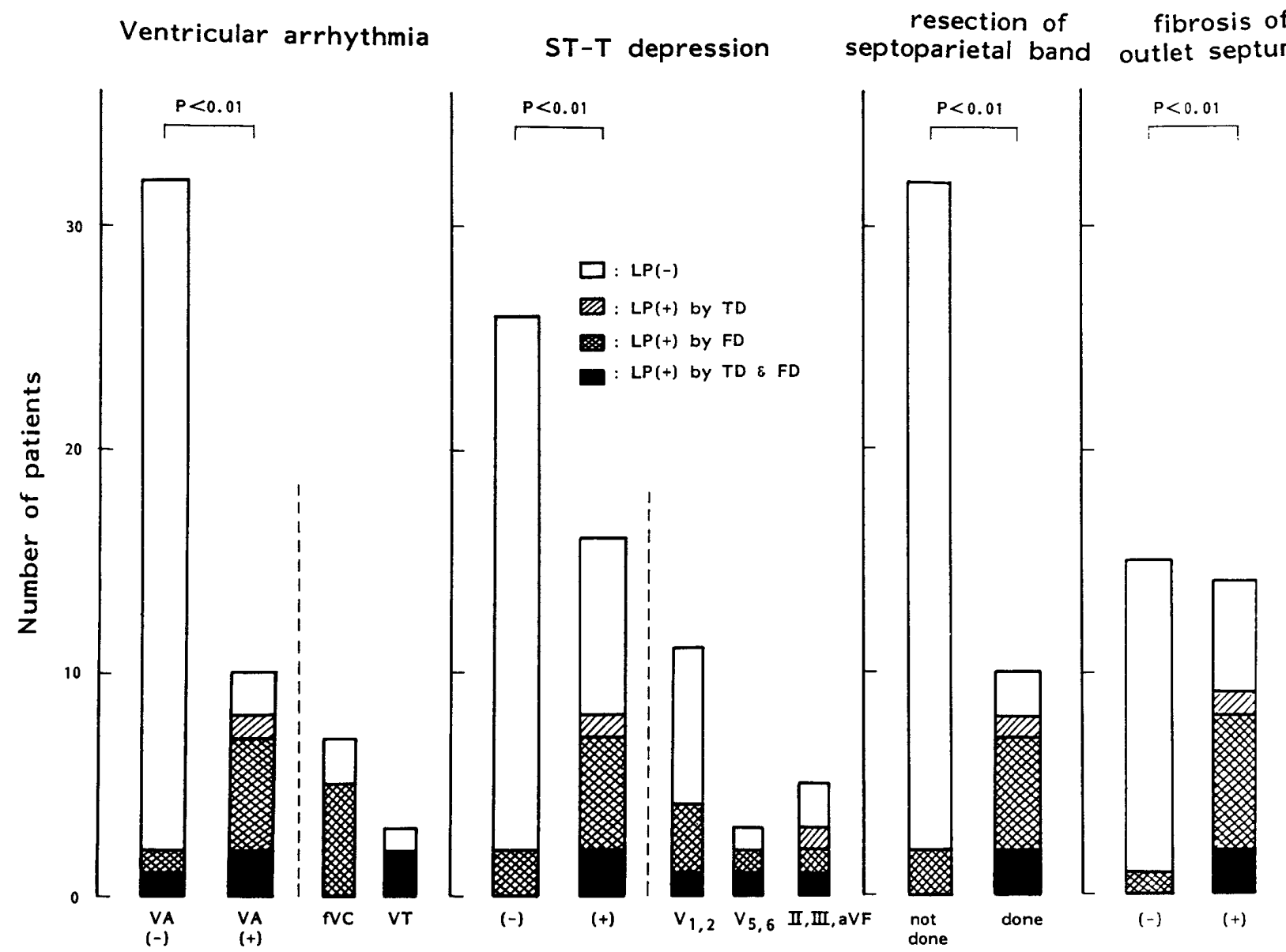

Fig.5. Clinical significance of abnormal SA-ECGs defined by time and/or frequency domain analysis.

The solid black areas show a patient with abnormal SA-ECGs which were defined by both time and frequency domain analysis. The cross-hatching shows potentials defined by frequency domain analysis (FT) and the diagonal lines show a case defined by time domain analysis (TD). Note that ventricular arrhythmias (Lown's grade III or higher), ST-T depression, a history of resection of a septoparietal muscle band, and histologically documented fibrosis of the outlet septum at operation, were more common in patients with abnormal SA-ECGs than in those without such potentials.

healthy volunteers. In the frequency domain analysis, none of the patients showed an abnormal low/high area ratio preoperatively (Fig. 4).

According to our criteria, abnormal SAECGs were found in $10 / 42$ postoperative, patients 3 by time domain analysis and 9 by frequency domain analysis (Tables I and II). The clinical profiles of the patients with abnormal SA-ECGs are shown in Table I and Fig. 5. Malignant ventricular arrhythmias (Lown's grade III or higher) were also noted in $10 / 42$ postoperative patients. Of, these 10,3 had asymptomatic nonsustained ventricular tachycardia and abnormal SAECGs, while 7 had asymptomatic premature ventricular contractions (Lown's grade III or higher). Five of these 7 patients also had abnormal SA-ECG.

The incidence of malignant ventricular arrhythmias was significantly greater in the patients with abnormal SA-ECGs than in those with normal SA-ECGs $(8 / 10$ versus $2 / 32, p<0.001)$. ST-T segment depression on standard ECG was observed during exercise in 16 postoperative patients; i.e., 11 in leads V1 and V2, 3 in leads V5 and V6, and patients with abnormal SA-ECGs than in those with normal SA-ECGs $(8 / 10$ versus $8 / 32, \mathrm{p}<0.002$ ).

All of our patients had undergone myectomy of the hypertrophic outlet septum 


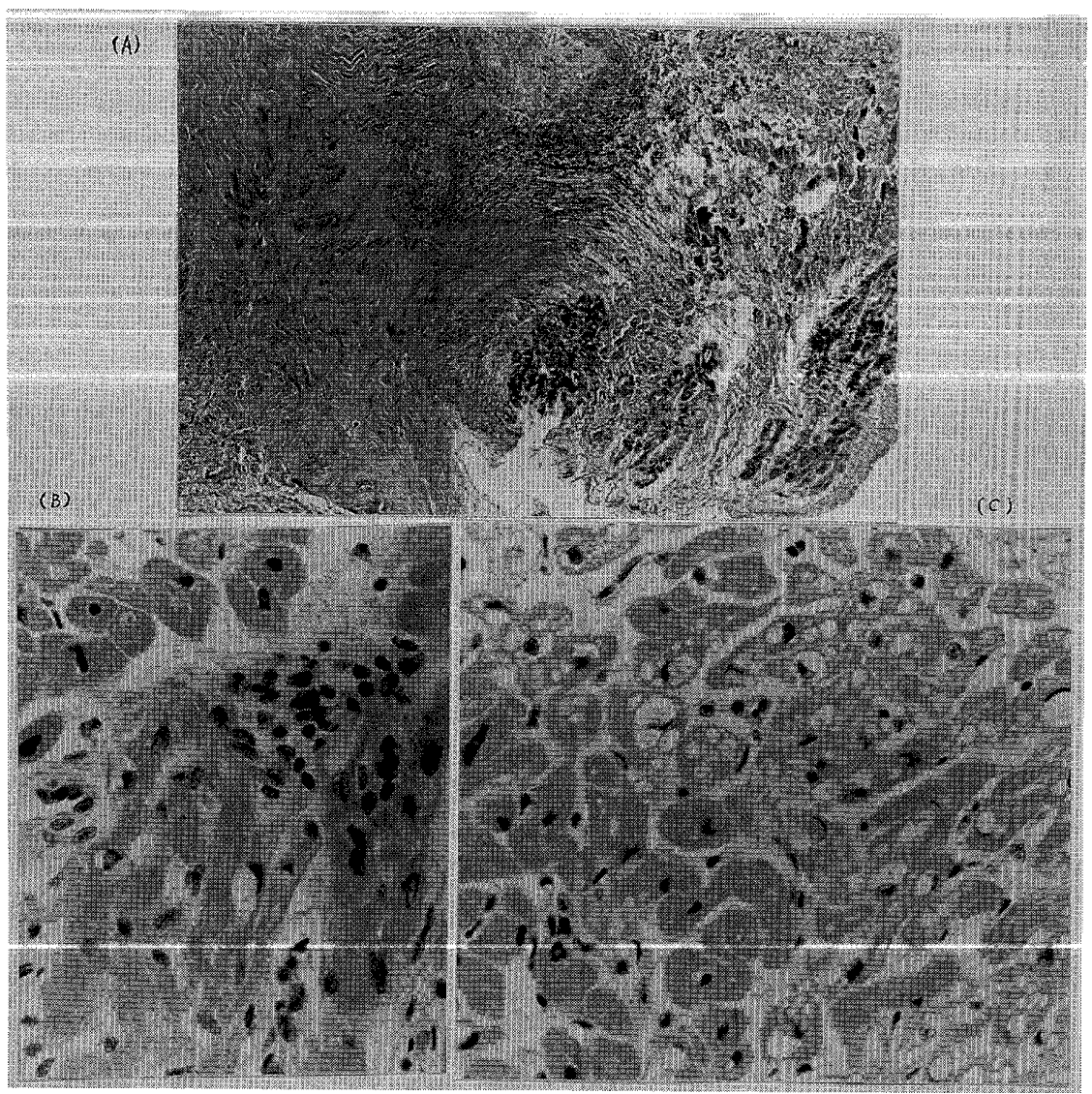

Fig.6. Representative histologic features of the hypertrophic right ventricular outlet septum in patient 1. Endocardial thickening due to marked fibrosis extending into the myocardium can be observed (upper fig.). Note the pyknotic myofibril nuclei and the vacuolar degeneration of the myofibril cytoplasm (lower fig.). (A: Mallory's azan stain; B \& C: hematoxylin-eosin stain).

and 10 patients had also received resection of the septoparietal muscle band that was contributing to infundibular stenosis. The SA-ECGs of patients undergoing septoparietal muscle band resection were more commonly abnormal than those of the patients who did not require such resection $(8 / 10$ versus $2 / 32, \mathrm{p}<0.001$ ) (Fig. 5). Histological examination showed simple hyperplasia of the normal myofibrils in 15 patients and abnormalities of the myocardium in 14 patients. These abnormal histological features included marked fibrosis of the endocardium extending into the myocardium in all 14 patients, numerous myofibrils with pyknotic nuclei in 7 patients, and a considerable numbers of myofibrils with vacuolated cytoplasm in 2 patients (Fig. 6). Myocardial fibrosis was observed in $9 / 10$ patients with abnormal SA-ECGs, and in $5 / 19$ patients with normal SA-ECGs $(p<0.002)$.

\section{DISCUSSION}

Delayed electrical activity may serve as an important component in the development of reentrant arrhythmias and the induction of triggered activity $6-8$ Recently, SA-ECG has been applied to postoperative patients using Simson's method. However, time domain analysis has some limitations, such as the cut-off noise level, the effects of ventricular conduction disturbance, and the difficulty of defining the onset and end points of the QRS complex. The use of frequency domain analysis has been claimed to solve these problems! 15,16

Zimmermann et $\mathrm{al}^{13}$ found abnormal SAECGs and spontaneous ventricular tachycardia in $11 / 34$ postoperative patients with tetralogy of Fallot. Stelling et $\mathrm{al}^{12}$ found that 10/31 postoperative patients with congenital heart disease ( $77 \%$ had tetralogy of Fallot) had inducible ventricular tachycardia and 
late potentials. In our series of 42 postoperative patients, abnormal SA-ECGs were seen in 3 patients by time domain analysis and 9 patients by frequency domain analysis. These incidences were low compared with previous studies using time domain analysis, and the difference may be due to the use of different criteria and methods for detecting late potentials and ventricular arrhythmias, or to different procedures used to relieve infundibular stenosis. Zimmermann et $\mathrm{al}^{14}$ defined late potentials as follows: a filtered QRS duration of $>140 \mathrm{msec}$ and a duration of low amplitude signal (LAS) of $>50 \mathrm{msec}$ in the presence of right bundle branch block. Stelling et al $^{12}$ predicted inducible ventricular tachycardia by using a root-mean-square voltage (RMS) $<100 \mu \mathrm{V}$ and a filtered-QRS duration $>128 \mathrm{msec}$. They achieved a sensitivity of $91 \%$ and a specificity of $70 \%$. The present study showed that time domain analysis alone was not sufficient to detect abnormal SA-ECGs and that frequency domain analysis considerably enhanced the detection of abnormal SA-ECG. Although the combination of both methods was more sensitive in predicting ventricular arrhythmias, 2/10 patients with ventricular arrhythmias did not show abnormal SA-ECGs. There are at least 2 possible explanations for this result: First, the ventricular arrhythmias in these patients may have been produced by a different mechanism, such as triggered activity or increased ventricular automaticity. Second, abnormal SA-ECGs may have been undetectable because they represented a discontinuous delayed action potential.

Studies performed before 1988 either excluded or neglected patients with ventricular conduction disturbance. In more recent studies ${ }^{14,17}$ the criteria of late potentials, i.e., the cut off point of the filtered-QRS duration, the duration of low amplitude signal (LAS), and the root-mean-square voltage (RMS), were altered in the presence of ventricular conduction disturbance. In this study, the late duration and the root-meansquare voltage (RMS) were used to define abnormal SA-ECGs in time domain analysis, instead of the filtered-QRS duration and the duration of low amplitude signal (LAS). In the presence of right bundle branch block, both of these parameters are markedly prolonged and patients with ventricular tachyar- rhythmias cannot be detected. In contrast, the late duration in the time domain and fast Fourier transformation pattern in the frequency domain were not influenced by ventricular conduction disturbance. Lindsay et al showed that frequency domain analysis at peak amplitude could be used to identify patients with coronary artery disease who were at high risk for ventricular tachycardia without the analysis being affected by bundle branch block ${ }^{15}$ After the repair of tetralogy of Fallot, ventricular conduction disturbance is a common finding, so frequency domain analysis seems to have a distinct advantage over time domain analysis.

Most patients with abnormal SA-ECGs has ST-T depression on standard electrocardiogram, a history of resection of a septoparietal muscle band, and myocardial fibrosis detected at operation. Autopsy studies of tetralogy of Fallot patients who died suddenly late after surgical repair have revealed extensive fibrosis affecting multiple areas of the right ventricle? Although it remains unclear whether this right ventricular fibrosis resulted from surgical intervention or was a part of the natural history of tetralogy of Fallot, residual myocardial hypertrophy and underlying myocardial damage seem to be related to the development of abnormal SAECGs. Epicardial and endocardial mapping studies have shown that the right ventricular outflow tract and right ventricular inflow septum were the most common sites for the reentrant origin of ventricular tachycardia in postoperative tetralogy of Fallot patients! 1,4 Some of those sites were consistent with the regions affected by infundibular resection!1 These findings suggest that abnormal SAECGs in postoperative tetralogy of Fallot patients may indicate underlying histological abnormalities secondary to prolonged hypoxia or ischemia of hypertrophic myocardium and subsequent surgical intervention for septoparietal bands. In addition, early surgical repair and avoiding injury to the septoparietal band are important in preventing the appearance of ventricular late potentials.

\section{REFERENCES}

1. DEANFIELD J, MCKENNA BW, ROWLAND E: Local abnormalities of right ventricular depolarization after repair of tetralogy of Fallot: A 
basis for ventricular arrhythmia. Am $J$ Cardiol 1984; 55: 522-525

2. GARSON A, PORTER CJ, GILLETTE PC, MCNAMARA DG: Induction of ventricular tachycardia during electrophysiology study after repair of tetralogy of Fallot. J Am Coll Cardiol 1983; 1: $1493-1502$

3. DEANFIELD JE, HO SY, ANDERSON RH, MCKENNA WJ, ALLWORK SP, HALLIDIESMITH K: Late sudden death after repair of tetralogy of Fallot: a clinicopathologic study. Circulation 1983; 67: 626-631

4. KUGLER JD, PINSKY WW, CHEATHAM JP, HOFSCHIRE PJ, MOORING PK, FLEMING WH: Sustained ventricular tachycardia following repair of tetralogy of Fallot: New electrophysiologic findings. Am J Cardiol 1983; 51: 1137-1143

5. KAVEY RW, BLACKMAN MS, SONDHEIMER HM: Incidence and severity of chronic ventricular dysrhythmias after repair of tetralogy of Fallot. Am Heart $J$ 1982; 103: 342-350

6. SIMSON MB, UNTEREKER WJ, SPIELMAN SR, HOROWITZ LN, MARCUS NH, FALCONE RA, HARKEN AH, JOSEPHSON ME: Relation between late potentials on the body surface and directly recorded fragmented electrograms in patients with ventricular tachycardia. Am J Cardiol 1983; 51: 105-112

7. JOSEPHSON ME, HOROWITZ LN, FARSHIDI A: Continuous local electrical activity. A Mechanism of recurrent ventricular tachycardia. Circulation 1978; 57: $659-665$

8. BERBARI EJ, SCHERLAG BJ, HOPE RR, LAZZARA R: Recording from the body surface of arrhythmogenic ventricular activity during the ST segment. Am J Cardiol 1978; 41: 697-701

9. BREITHARDT G, CAIN ME, EL-SHERIF N, FLOWERS N, HOMBACH V, JANSE M, SIMSON MB: Standards for analysis of ventricular late potentials using high resolution or signal-averaged electrocardiography. Eur Heart J 1991; 12: $473-480$
10. AIZAWA Y, ODA H, SATOH M, MURATA M, SHIBATA A, EGUCHI S: Transient entrainment of ventricular tachycardia with continuous local electrical activity. Am Heart J 1987; 114: 182-184

11. HOROWITZ LN, VETTER VL, HARKEN AH, JOSEPHSON ME: Electrophysiologic characteristics of sustained ventricular tachycardia occurring after repair of tetralogy of Fallot. Am J Cardiol 1980; 46: 446-452

12. STELLING JA, DANFORD DA, KUGLER JD, WINDLE JR, CHEATHAM JP, GUMBINER CH, LATSON LA, HOFSCHIRE PJ: Late potentials and inducible ventricular tachycardia in surgically repaired congenital heart disease. Circulation 1990; 82: $1690-1696$

13. ZIMMERMAN M, FRIEDLI B, ADAMEC R, OBERHANSLI I: Frequency of ventricular late potentials and fractioned right ventricular electrograms after operative repair of tetralogy of Fallot. Am J Cardiol 1987; 59: 448-453

14. ZIMMERMANN M, FRIEDLI B, OBERHANSLI I: Ventricular late potentials and induced ventricular arrhythmias after surgical repair of tetralogy of Fallot. Am J Cardiol 1991; 67: 873-878

15. LINDSAY BD, MARKHAM J, SCHECHTMAN $\mathrm{KB}$, AMBOS HD, CAIN ME: Identification of patients with sustained ventricular tachycardia by frequency analysis of signal-averaged electrocardiograms despite the presence of bundle branch block. Circulation 1988; 77: 122-130

16. HABERL R, JILGE G, PULTER R, STEINBECK G: Comparison of frequency and time domain analysis of the signal-averaged electrocardiogram in patients with ventricular tachycardia and coronary artery disease: Methodologic validation and clinical relevance. J Am Coll Cardiol 1988; 12: $150-158$

17. BUCKINGHAM TA, THESSEN CC, STEVENS LL, REDD RM, KENNEDY HL: Effects of conduction defects on the signal-averaged electrocardiographic determination of late potentials. $A m J$ Cardiol 1988; 61: 1265-1271 